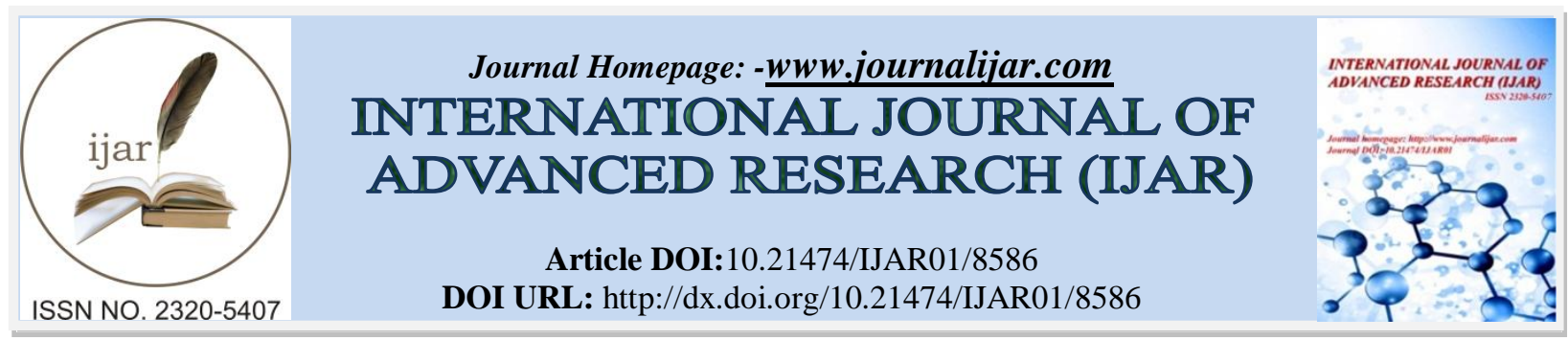

RESEARCH ARTICLE

\title{
EFFECT OF SPERMIDINE (SPD) ON PHYSIOLOGICAL AND BIOCHEMICAL RESPONSES IN ZEA MAYS L. UNDER UV-B STRESS.
}

K.Bavithra ${ }^{1}$, S. Muthulakshmi ${ }^{2}$ and K. Lingakumar ${ }^{1}$.

1. Centre for Research and Postgraduate Studies in Botany, Ayya Nadar Janaki Ammal College (Autonomous ), Sivakasi, Tamil Nadu, India.

2. Department of Botany with specialization in Plant Biotechnology, The Standard Fireworks Rajaratnam College for Women, Sivakasi, Tamil Nadu, India.

\section{Manuscript Info}

Manuscript History

Received: 14 December 2018

Final Accepted: 16 January 2019

Published: February 2019

Key words:-

Spermidine, UV-B stress, Zea mays, physiological and Biochemical.

\section{Abstract}

Ultraviolet-B (UV-B) radiation is one of the most important abiotic stress factors that could influence plant growth, development and productivity. Spermidine (Spd) is an important plant growth regulator involved in a wide variety of physiological processes. The study was carried out to investigate the protective role of exogenous on alleviation of UV-B stress in Zea mays L. Our result showed that UV-B stress significantly decreased the growth parameters, total soluble sugars, aminoacid, proline content, superoxide dismutase (SOD), catalase (CAT), peroxidase activity (PD) and Malondialdehyde content (MDA) in both the seedlings, but the combination of Spd pretreatment and UV$B$ enhanced the vegetative growth characters such as shoot and root length, shoot and root fresh weights and dry weights, photosynthetic pigment, non photosynthetic pigment composition and total soluble protein, total soluble glucose, free amino acid, SOD, CAT, PD, MDA and NR activities. However, UV-B stress induced positive effects on growth characters and biochemical constituents. Therefore appropriate concentration of Spd could be used as a simple, practical and inexpensive method for modulating the effects of UV-B stress in plants.

Copy Right, IJAR, 2019,. All rights reserved.

\section{Introduction:-}

Abiotic stresses are serious threats to agriculture and result in the deterioration of the environment and of crop loss worldwide, reducing average yields for most crop plants by more than 50\% (Wang et al., 2003). Ultraviolet (UV) B radiation (280-315) is a natural component of sunlight. Due to ozone depletion, the amount of UV-B radiation reaching the earth's surface has increased over the last decades. The climate of the earth is currently as a results of the emission of $\mathrm{CO}_{2}$ chlorofurocarbons (CFCs), $\mathrm{CH}_{4}$ and $\mathrm{N}_{2} \mathrm{O}$ into the atmosphere (Stolari et al., 1991; WMO 1994). Numerous studies have shown that exposure to UV-B radiation can result in the altered morphology of higher plants.

Plants hormones are involved in responses to abiotic stress (e.g. heat and cold, drought and flooding), and biotic stress (e.g. herbivory and pathogenicity). During the normal processes of growth and development, plants are subjected to different type of stresses, such as drought, ultraviolet light, air pollution and pathogen attack. Most of

Corresponding Author:- K. Lingakumar.

Address:- Department of Botany with specialization in Plant Biotechnology, The Standard Fireworks

Rajaratnam College for Women, Sivakasi, Tamil Nadu, India. 
the plants suffer from both physiological and biochemical damage by exposure to high temperature or low temperature.

Polyamines are a group of aliphatic amines, organic polycations having variable hydrocarbon chains and two or more amino groups, cationic at neutral $\mathrm{pH}$, that are essential for cell growth and viability. Because of their positive charges, polyamines are able to bind by electrostatic linkages to many cellular macromolecules, including DNA, RNA, and proteins (Kusano et al., 2008). It involved in the regulation of a diverse range of vital cellular processes in both eukaryotic and prokaryotic cells, including cell proliferation, signal transduction and membrane stabilization (Wang et al., 2003; Kusano et al., 2008). The diamine putrescine and triamine spertmidine are found in nearly all organisms and are that most abundant polyamines in prokaryotic cells, such as bacteria, while the tetraamine spermine is mainly found in eukaryotic cells. In plants the most common polyamines and putrescine, spermidine and spermine (Tiburcio et al., 1993; Grimes et al., 1986). These are found in all the living organism and are responsible for different functions. The biological functioning of all them is similar. These occur in different forms free living, conjugated and titers. (Tang et al., 2004). Which are present in free amines, conjugated to small molecules such as hydroxycinnamic acid, or bound to larger macromolecules such as proteins or nucleic acids. Less common polyamines found in plants are cadaverine, and the spermidine and spermine related compounds, homospermidines, polyamines are involved in many aspects of plant development (Martin- Tauguy, 2001; Li\& Burritt, 2003; Hunter \& Burritt, 2005; Baron \& Stasolla, 2008) and are important molecules associated with both abiotic and biotic stress tolerance (Burritt, 2008).

\section{Materials And Methods:- Cultivation of seedlings:-}

Healthy and uniform seeds of Zea mays L. were purchased from Agricultural Research Centre, Kovilpatti. The percentage of seed germination was found to be $80-85 \%$. The seeds were sown in pots containing a mixture of red soil, black soil and sand mixed in the ratio of 2: 2: 1 . Soon after emergence of the cotyledons, the seedlings were shifted to daylight conditions. Since the ambient climate was too hot for the seedlings, a $40 \%$ cut off mesh filter was used to surround the pots for an initial period of 2-3 days.

\section{SpermidineTreatment:-}

Spermidine was obtained from Sigma Chemical Co. (St. Louis, U.S.A). Spd was initially dissolved in $100 \mu 1$ of waterl and made up to $0.5 \times 10^{-6} \mathrm{M}$ to $5 \times 10^{-6} \mathrm{M}(\mathrm{pH}, 6.5)$ and distilled water containing $0.02 \%$ Tween-20 (Polyoxyethylenesorbitanmonolaurate). The foliar spray was given for three days early in the morning and growth analyses were done after 10 and 20 days of seedling growth. The seedlings were sprayed with solutions until dropping with an atomic sprayer. Plants sprayed with $0.02 \%$ Tween- 20 only served as the control.

\section{UV-B treatment:-}

Seedlings (days after emergence) were exposed to short-term UV-B irradiation. The square-wave supplementation system was used to provide desired UV-B radiation, delivered at a constant rate from $0.5 \mathrm{~m}$ above the plant canopy for $15 \mathrm{~min} / \mathrm{d}$ for 3 days at $1 \mathrm{~W} . \mathrm{m}^{-2}$ by four fluorescent UV-313 lamps (Q Panel, Cleland, U.S.A.) driven by $40 \mathrm{~W}$ dimming ballasts. The simulated $\mathrm{O}_{3}$ depletion was $6-24 \%$. UV-B radiation at the plant surface was $400 \mathrm{~mW} . \mathrm{m}^{-2} . \mathrm{s}^{-1}$. The amount of energy delivered at the top of the plant canopy was measured with a Spectroradiometer (IL-700, International Lights, U.S.A) equipped with a broadband light sensor (type SEE 400). Although the instrument is outdated, the radiation measurement procedure remained the same as reported by Lingakumar and Kulandaivelu (1998).

After two days of the treatment the seedlings of Zea mays L. were used for measuring the growth parameters such as such as root length, shoot length, leaf area, fresh weight and dry weight were measured. The biochemical and enzymatic characters were analyzed by the following methods: chlorophyll and carotenoids (Wellburn and Lichtenthalar, 1984), Anthocyanin and Flavonoid Mirecki and Teramura (1984), Total soluble sugar (Jayaraman, 1981), Protein content (Lowry et al., 1951), in vivo nitrate reductase activity (Jaworski, 1971), Superoxide dismutase activity (SOD) Bowler et al. (1992) and Malondialdehyde content Heath and pacher (1968). 


\section{Results And Discussion:- \\ Effect of UV-B radiation and Spd on morphological parameters:-}

Exposure of UV-B radiation to 10 and 20 days old seedlings of experimental plants induced changes in leaf and plant morphology. UV-B induced wilting, due to reduced size of xylem vasculature resulting in low water uptake (Lingakumar and Kulandaivelu, 1993). In this study UV-B stress to Zea mays plants decreased leaf area, dry weight of foliage and plant height as observed by An et al., (2004).

\section{Effect of UV-B radiation and Spd on biochemical constituents:-}

In this contribution, we studied the effects of exogenous spd on the plant growth, chlorophyll contents, photosynthesis, of Zea mays exposed to UV stress. It was shown that spd could amelinate the inhibition of photochemical efficiency induced by UV stress.

Zea mays with spd better then seedlings without spd under UV. This results agrees with a previous study by (Duran et al., 2008). In this study, we found that spd is also involved in the protection of photosynthetic pigments content under UV stress. Spermidine induced an increase in the amount of both total chla, chlb, and chla+b ratios as compared with non spd treated UV stressed plants.

However exogenous application of spd increased significantly the content of Chlorophyll (Chl a, Chl b, Total chl and Carotenoid) content in both the seedlings (Fig 1). This phenomenon enhanced by spd was similar to the results obtained by Chattopadhayay et al. (2002) As a result, exogenous spd can alleviated the reduction of photosynthetic pigments content and improve the growth of Zea mays seedlings.

The total sugar content initially increased but declined afterward. Increased total sugar levels are possibly due to enhanced fruit ripening and senescence. However the maximum significant difference of sugar content among all treatments, Bhagwan et al. (2000) and Malik et al. (2003) also reported that post-harvest put application preserved sugar in tomatoes and mangoes when compared with the control. The decrease in the protein found only in UV-B treated Zea mays. Our results are in accordance with the increase protein content in all the concentration after UV-B exposure.

Nitrate reductase is a key enzyme in the nitrogen metabolism and assessment of this enzyme activity would be an indication of morphological status of a plant. In the present study, an increase in NR activity under spd treatment proves to be a positive response of the phytohormone viz., spd. Besides inducing NR activity, spd was also found to have regulatory role in UVB induced changes. Maximum response was noticed with Spd at $1 \mathrm{mM}$. SOD is an enzyme found to be expressed in plant and other animal systems especially at times of stress. The present study increase in SOD activity corresponds to the alleviation of UV-B stress by the application of Spd. Spermidine at various concentrations was able to bring about not much changes in SOD activity. Spd was found to be effective only in short-term UV-B irradiated seedlings. The SOD activity was greater in Zea mays.

The alterations found in MDA content were best expressed at the beginning of the experiment and diminished with time. Application of spd only did not alter significantly the MDA level. The significant accumulation of MDA concentration found after UV-C exposure indulges the presence of oxidative stress damages in the membranes of Zea mays seedlings. It has been reported that polyamine accumulation in plant cells can reduce chilling injury (Ferdowsi, 2015). Genetic modification of polyamine biosynthetic pathway was belived to be an useful tool to recognize the funtion of polyamines in plant responses to abiotic stress in plant (Igarasi and Kashiwagi, 2000; Childs et al., 2003; Kusano et al., 2008)
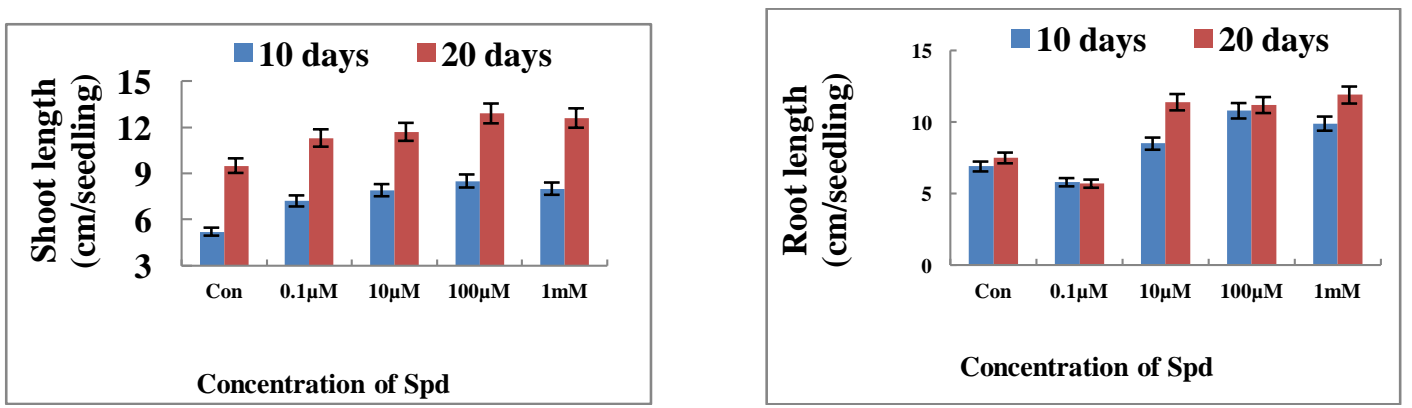

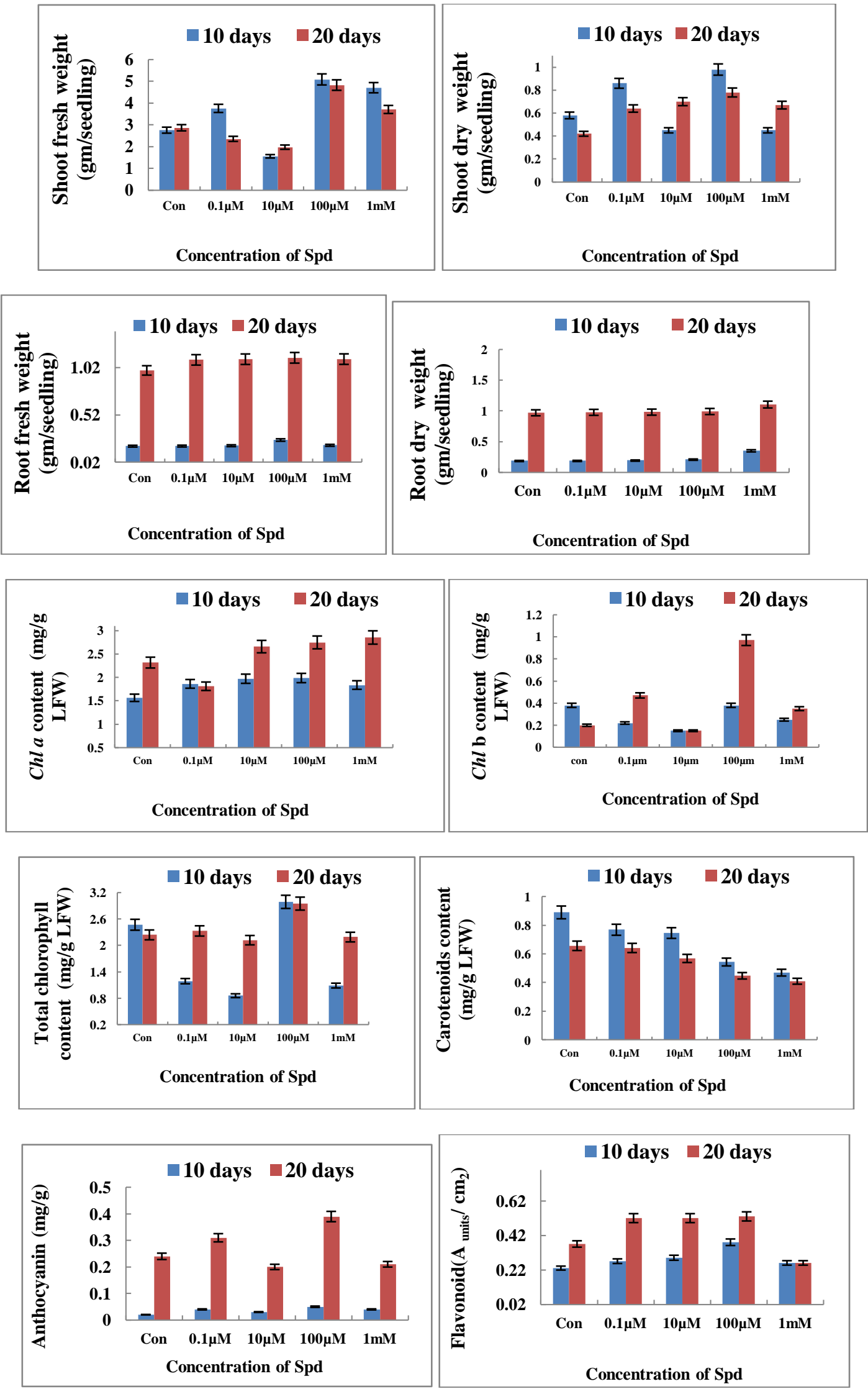

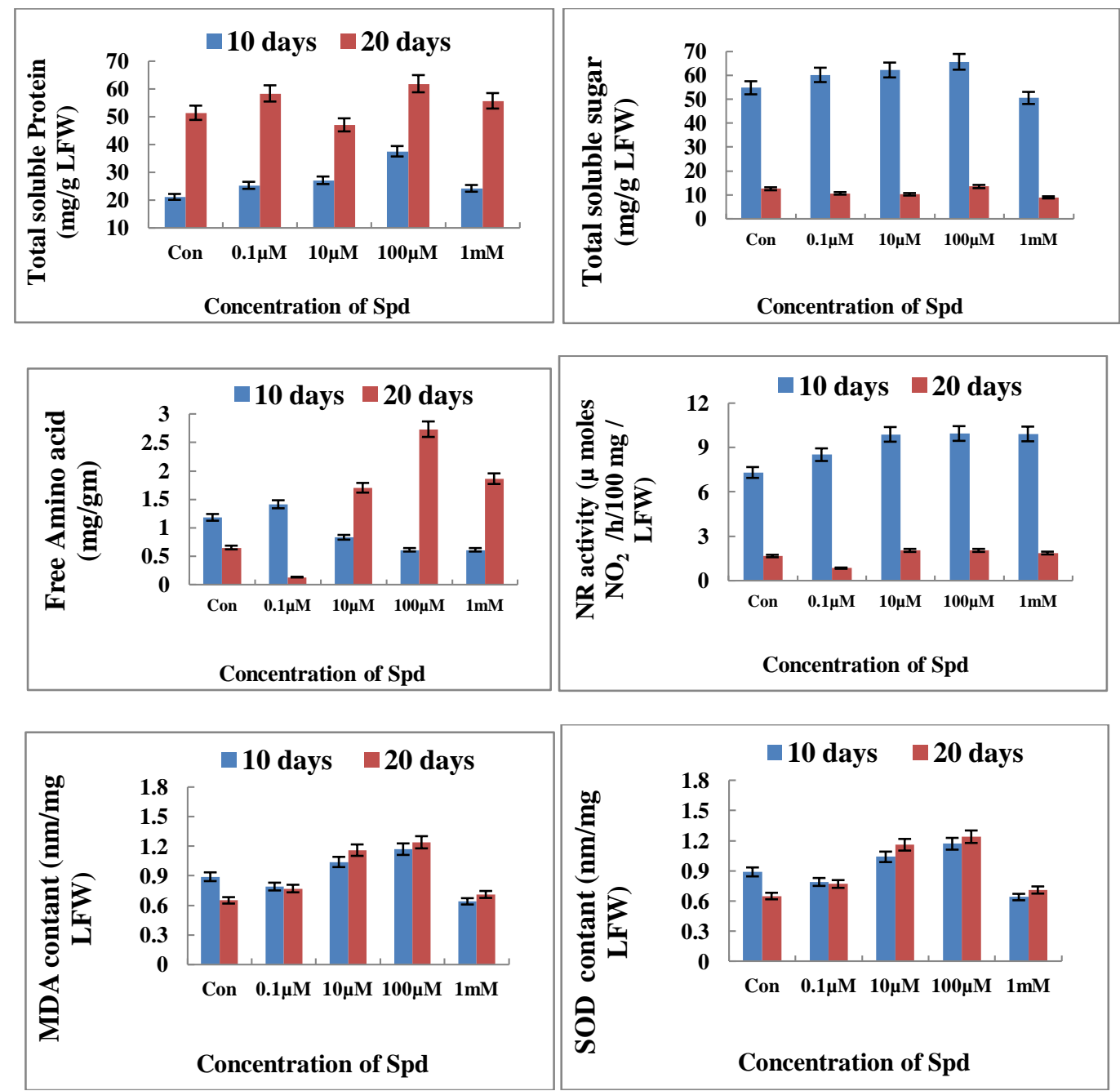

Fig.1:-Effect of different days of Spd+UV on photosynthetic pigments,Non photosynthetic pigments, biochemical and Enzyme activity of Zea mays. The measurements were made in 10 and 20 -d- old seedlings. The values are an average of 5 independent measurements. Mean \pm SE, $n=5$.

\section{Conclusion:-}

SNP has a good potential in improving accumulation of Biochemical composition. The concentrations of $100 \mu \mathrm{m}$ and $10 \mathrm{mM}$ of SNP give the best results. So, the farmers may be advised to make up of SNP for improving growth and development of Zea mays

\section{Acknowledgement:-}

The authors are thankful to the Management and Principal for providing the necessary facilities to carry out the experiments.

\section{References:-}

1. Aworski, E.G. (1971). Nitrate reductase activity assay in intact plant tissue. Biochem. Biophys. Res. Commun. 43: 1274-1279 Plantation and Natural forest in Amarkantak. Indian Forester. 2: 240 - 250.

2. Baron, K., Stasolla, C. (2008). The role of polyamines during in vivo and in vitro development. In vitro cellular \& Developmental. Biology- Plant. 44: 384-395.

3. Bates, L.S., Waldren, R.P., and Teare, I.T. (1973). Rapid determination of proline for water stress studies. Plant Sci. 2: 205-207. 
4. Bowler, C.,Van Montagu, M. and Inze, D. (1992). Superoxide dismutase and stress tolerance. Plant Physiol. Plant Mol. Biol. 43: 83-116.

5. Burritt, D.J. (2008). The polycylic aromatic hydrocarbon phenanthrene causes oxidative stress and alters polyamine metabolism in the aquatic liverwort Riccia fluitans L. Plant Cell \& Environment. 31: 1416-1431.

6. Chattopadhayay, M.K., Tiwari, B.S., Chattopadhayay, G., Bose, A., Sengupta, D.N., Ghosh, B. (2002). Protective role of exogenous polyamines on salinity stressed rice (Oryza sativa) plants. Physiol. Plant. 116: 192-199.

7. Duran, H.G., Shu, Y., Liu, D.H., Qin, D.H., Liang, H.G., Lin, H.H. (2006). Effects of exogenous spermidine on photosystemII of wheat seedlings under water stress. J. Integr. Plant Biol. 48: 920- 927.

8. Heath, R.L. and Packer, L. (1968). Photoperoxidation in isolated chloroplasts: I. Kinetics and stoichiometry of fatty acid peroxidation. Archives of biochemistry and biophysics. 125: 189-198.

9. Hunter, K., Burritt, D.J. (2005). Light quality influences the polyamine content of lettuce (Lactuca sativa L.) cotyledons explants during shoot production in vitro. Plant Growth Regulation. 45:53-61.

10. Igarashi, K., Kashiwagi, K. (2000). Mysterious modulators of cellular function. Boichemical \& Biophysical Research Communications. 271: 559-564.

11. Jayaraman, J. (1981). Laboratory Manual in biochemistry, Wiley Eastern Limited, Madras. 180.

12. Kusano, T., Berberich, T., Tateda, C.,Takahashi, Y. (2008). Polyamines essential factors for growth and survival. Planta. 228: 367-381.

13. Li, Z.L., Burritt, D.J. (2003). Changes in endogenous polyamines during the formation of somatic embryos from isogenic lines of Dactylis glomerata L. with different regenerative capacities. Plant Growth Regulation. 40: 65-74.

14. Lingakumar, K., Kulandaivelu, G. (1998). Differential response of growth and photosynthesis in cyamopsis tetragonoloba L. grown under ultraviolet-B and supplemental long wavelength radiations. Photosynthetica. 35: 335- 343.

15. Malik, A.U., Singh, Z. (2003). Abscission of mango fruitlets as influenced by biosynthesis of polyamines . Journal of Horticulture Science and Biotechnology. 78: 721-727.

16. Mancinelli, A.L., Yang, C., Lindquist, P., Anderson, O.R., and Rabino, I. (1975). Photocontrol of anthocyanin synthesis. III. The action of streptomycin on the synthesis of chlorophyll and antocyanin. Plant Physiol. 55: 251-257.

17. Martin- Tanguy, J. (2001). Metabolism and function of polyamines in plants. Plant Growth Regulation. 34: 135148.

18. Mirecki, R.M., and Teramura, A.H. (1984). Effects of ultraviolet-B irradiance on soybean. The dependence of plant sensitivity on the photosynthetic photon flux density during and after leaf expansion. Ind. J. Plant physiol. 74: 478-480.

19. Stolari, R.S., Bloomfield, P. \& Mcpeters, R.D. (1991). Total zone trends deduced from Nimbus 7 TOMS data. J. Geophys. Res. Lett. 18: 1015- 1018.

20. Tang, w., Ronald, JN., Outhavong, V. (2004). Exogenously added polyamines recover browining tissues in to normal callus cultures and improve plant regeneration in pine. Physiology Plantarum. 122: 386- 395.

21. Tiburico, A.F., Campos, J.L., Figueras, X., Besford, R.T. (1993). Recent advances in the understanding of polyamine functions during plant development. Plant Growth Regulation. 12: 331-34.

22. Wang, W., Vinocur, B., Altman, A. (2003). Plant responses to drought, salinity and extreme temperatures: towards genetic engineering for stress tolerance. Planta. 218: 1-14.

23. Wellburn, A.R. and Lichtenthaler, H. (1984). Formulae and program to determine total carotenoids and chlorophyll a and b of leaf extracts in different solvents. In: Advances in Photosynthesis Research (Sybesma, C. ed.,) Martinus Nijhoff / Dr. W. Junk, The Hague. 2: 9-12. 